\title{
SEEDLING QUALITY - SOIL FERTILITY RELATIONSHIPS OF WHITE SPRUCE, AND RED AND WHITE PINE IN NURSERIES ${ }^{1}$
}

\author{
By ALEXANDER DICKSON, ALBERT L. LEAF and JOHN F. HOSNER ${ }^{2}$
}

\section{ABSTRACT}

An index based on combined morphological features of seedlings was used to relate seedling quality to different levels of nursery soil fertility as determined by soil and seedling analyses. Nutrient content on a per seedling basis was closely related to seedling quality.

\section{INTRODUCTION}

The forest tree nurseryman is obligated to turn out planting stock in quantity that will exhibit high rates of survival and growth in the often-rigorous field environment. Proper nursery soil management practices are necessary to meet this obligation. Periodic soil and seedling analyses are prerequisites for good soil management.

This paper discusses the relationship of soil fertility levels as determined by soil and seedling analyses to the quality of 2-0 white spruce, red pine and white pine seedlings grown at four northeastern United States nurseries.

\section{Materials AND MEthods}

The four nurseries in which the soil and seedlings were sampled are located at Essex Junction, Vermont; and Saratoga, Lowville and Oak Orchard, New York. All four nurseries were subject to essentially the same gross environmental influences. The soils of the nurseries are generally of similar coarse texture and glaciofluvial origin, but vary in depth to difficultly pervious strata: Essex Junction nursery soil is of the Adams series; Saratago nursery soil is in the Merrimac series; Lowville nursery soil includes Duane and Colton series; and Oak Orchard nursery soil includes Ottawa and Berrien series. The surface six inches of the soils from the four nurseries are sandy in texture with a silt-plus-clay content ranging from approximately 5.5 to 20 per cent and organic matter content of approximately 2.5 to 7.5 per cent, though in most cases the organic matter does not exceed 6.0 per cent. The soil reaction ranged mainly between $\mathrm{pH} 4.4$ and 5.7 , but there were a few cases above and below this range (Table 1 ).

Samples of soil and 2-0 white spruce, and white and red pine seedlings were obtained from three $36 \times 6$ inch plots within each species in each nursery laid out in seedbeds with the long axis of the plots at right angles to that of the seedbed rows. Thus, six inch buffer strips were left on both edges of the

\footnotetext{
${ }^{1}$ Contribution from the Department of Silviculture, State University College of Forestry at Syracuse University, Syracuse 10, New York.

? The authors are Extension Forester, Department of Natural Resources, Saskatchewan, Canada; Assistant Professor of Silviculture; and Associate Professor of Forestry, Southern Illinois University (Visiting Professor of Silviculture 1958-59), respectively. Their biographies are in For. Chron. 36(1): 10. Appreciation is expressed to Mr. R. E. Farrington of the Vermont Department of Forest and Parks, Mr. E. Eliason of the New York Conservation Department and their respective staffs for their co-operation.
} 
TABLE 1

Relationship of Seedling Quality Indices of 2-0 White Spruce, White Pine and Red Pine in Four Northeastern U.S. Nurseries to Analysis of Surface 6 Inches of Soll Supporting These Seedlings

\begin{tabular}{|c|c|c|c|c|c|c|c|c|}
\hline \multirow{4}{*}{$\begin{array}{c}\text { Quality } \\
\text { Seedling } \\
\text { Quality } \\
\text { Index }\end{array}$} & \multicolumn{8}{|c|}{ Soil Analysis } \\
\hline & \multirow{2}{*}{$\begin{array}{l}\text { Silt } \\
\text { plus } \\
\text { Clay }\end{array}$} & \multirow{3}{*}{$\begin{array}{c}\begin{array}{c}\text { Organic } \\
\text { Matter }\end{array} \\
\text { ent }\end{array}$} & \multirow{3}{*}{$\frac{\text { Reaction }}{\text { pH }}$} & \multicolumn{2}{|c|}{ Total A vailable } & \multicolumn{3}{|c|}{ Exchangeable } \\
\hline & & & & $\mathrm{N}$ & $\mathbf{P}$ & $\mathbf{K}$ & $\mathbf{C a}$ & $\overline{\mathbf{M g}}$ \\
\hline & \multirow{2}{*}{\multicolumn{2}{|c|}{ per cent }} & & \multirow{2}{*}{\multicolumn{2}{|c|}{$\begin{array}{c}\text { p.ct. } \\
\text { SPRUCE }\end{array}$}} & \multirow{2}{*}{\multicolumn{3}{|c|}{ pounds per acre }} \\
\hline \multicolumn{2}{|c|}{ 2-0 WHITE SPRUCE } & & & & & & & \\
\hline 0.46 & 11.1 & 2.8 & 4.2 & 0.05 & 226 & 32 & 149 & 20 \\
\hline 0.25 & 11.0 & 2.7 & 4.4 & 0.08 & 243 & 44 & 176 & 20 \\
\hline 0.20 & 9.8 & 3.4 & 4.4 & 0.06 & 192 & 35 & 100 & 20 \\
\hline 0.15 & 11.1 & 5.8 & 4.4 & 0.23 & 226 & 139 & 1078 & 54 \\
\hline 0.14 & 9.8 & 5.8 & 4.5 & 0.15 & 240 & 133 & 1143 & 76 \\
\hline 0.11 & 13.9 & 6.4 & 4.4 & 0.20 & 184 & 119 & 873 & 49 \\
\hline 0.070 & 10.2 & 3.3 & 5.3 & 0.09 & 95 & 144 & 1931 & 22 \\
\hline 0.065 & 12.2 & 4.1 & 5.4 & 0.11 & 67 & 190 & 2301 & 92 \\
\hline 0.061 & 5.4 & 2.2 & 5.7 & 0.06 & 50 & 82 & 3286 & 97 \\
\hline 0.056 & 5.4 & 2.6 & 6.2 & 0.08 & 52 & 85 & 2281 & 80 \\
\hline 0.046 & 16.8 & 4.7 & 5.3 & 0.16 & 126 & 246 & 2950 & 43 \\
\hline 0.038 & 5.3 & 2.5 & 6.2 & 0.09 & 39 & 69 & 2922 & 118 \\
\hline \multicolumn{9}{|c|}{$2 \sim 0$ WHITE PINE } \\
\hline .27 & 11.4 & 3.1 & 4.3 & 0.05 & 151 & 40 & 123 & 18 \\
\hline .22 & 12.6 & 3.1 & 4.4 & 0.06 & 201 & 59 & 256 & 40 \\
\hline .19 & 11.4 & 3.0 & 4.3 & 0.06 & 186 & 28 & 149 & 19 \\
\hline .15 & 11.2 & 3.2 & 4.8 & 0.10 & 111 & 91 & 844 & 19 \\
\hline .13 & 10.8 & 3.4 & 4.9 & 0.11 & 123 & 92 & 643 & 19 \\
\hline .12 & 11.8 & 4.3 & 4.9 & 0.10 & 272 & 87 & 1289 & 52 \\
\hline .11 & 14.8 & 4.4 & 4.9 & 0.11 & 238 & 109 & 1514 & 57 \\
\hline .11 & 7.2 & 2.7 & 4.9 & 0.06 & 81 & 54 & 572 & 20 \\
\hline .082 & 12.8 & 3.8 & 5.0 & 0.11 & 247 & 108 & 1644 & 82 \\
\hline .057 & 8.3 & 3.6 & 5.7 & 0.12 & 74 & 95 & 3784 & 114 \\
\hline .054 & 11.3 & 4.4 & 5.7 & 0.15 & 74 & 116 & 3430 & 103 \\
\hline .042 & 13.4 & 5.4 & 6.2 & 0.15 & 50 & 142 & 4682 & 220 \\
\hline \multicolumn{9}{|c|}{$2-0$ RED PINE } \\
\hline .31 & 9.6 & 3.2 & 4.3 & 0.06 & 254 & 44 & 235 & 39 \\
\hline .19 & 11.7 & 3.1 & 4.4 & 0.07 & 199 & 70 & 228 & 21 \\
\hline .16 & 16.8 & 3.5 & 4.8 & 0.07 & 253 & 68 & 701 & 39 \\
\hline .11 & 15.4 & 4.6 & 5.2 & 0.10 & 59 & 194 & 1623 & 23 \\
\hline .083 & 12.4 & 4.2 & 5.6 & .09 & 83 & 197 & 1954 & 92 \\
\hline .067 & 19.2 & 6.3 & 5.7 & .18 & 47 & 77 & 3013 & 134 \\
\hline .056 & 18.1 & 6.4 & 5.7 & .22 & 58 & 73 & 4630 & 120 \\
\hline .054 & 12.7 & 5.7 & 4.4 & .11 & 190 & 166 & 485 & 18 \\
\hline .049 & 13.6 & 4.4 & 5.3 & .14 & 117 & 224 & 2666 & 84 \\
\hline .047 & 9.7 & 5.2 & 4.4 & .13 & 126 & 136 & 485 & 15 \\
\hline .046 & 11.7 & 4.8 & 4.4 & .15 & 123 & 133 & 514 & 17 \\
\hline .038 & 19.2 & 7.4 & 5.6 & .22 & 43 & 83 & 3396 & 178 \\
\hline
\end{tabular}


seedbeds to reduce edge-effect variation. The plots for each species were randomly selected in rows of as nearly uniform stocking and seedling size as possible at the four nurseries.

Seedling density was determined, and fifty seedlings in a strip parallel to the long axis and within each plot were clipped at the ground line for height and diameter measurements. Some twenty intact seedling in their respective nursery soils were transferred to the laboratory for analysis including fresh and dry weights of tops and roots, top-root ratio, and contents of nitrogen, phosphorus, potassium, calcium and magnesium (Wilde and Voigt, 1955).

Samples of the surface six inches of soil were obtained from each plot and transferred to the laboratory for analysis including texture, organic matter content, reaction, and levels of nitrogen, phosphorus, potassium, calcium and magnesium (Wilde and Voigt, 1955).

The seedling quality index was based upon certain morphological characteristics of the stock. The method of determining the index was according to Dickson et al. (1960) as follows:

Quality Index $=$ Drg Seedling Weight (gms.)

Height (cm.) / Diameter (mm.) Quotient + Top (gms.) / Roor (gms.) Ratio

In this index the dry seedling weight is heavily weighted, but the heightdiameter quotient and top-root ratio are also considered. Thus, the quality index is lowered accordingly if the seedlings are spindly or unbalanced.

Stock Quality Related to Soil and Seenling Analyses

Seedling quality according to the index ranged (good to poor) from 0.460 to 0.038 for white spruce, 0.266 to 0.041 for white pine, and 0.310 to 0.038 for red pine, respectively.

The nutrient levels of the soils varied considerably between plots and differed from the suggested standards of fertility for soils supporting white spruce, and red and white pine. Except for the available phosphorus contents, the soil fertility levels in many cases were considerably below the suggested standards of approximately 0.12 per cent total nitrogen, 30 pounds per acre available phosphorus, 200 pounds per acre exchangeable potassium, 1,000 pounds per acre exchangeable calcium, and 250 pounds per acre exchangeable magnesium (Wilde, 1958). There was a lack of correlation between the results of soil analysis and the seedling quality indices (Table 1). This lack of correlation probably was due in part to the deficiencies of several of the nutrient elements in the soils and the effect of their interactions, and also to the variation in densities of stocking.

The factors of seedling production vary considerably between plots and differ from suggested levels of seedling density and dry weight production for 2-0 white spruce, and red and white pine (Table 2). The stocking densities varied from $122-0$ white spruce to $2052-0$ red pine seedlings per square foot and the white pine seedlings fell within this range. The suggested level of stocking for these species is approximately 50 seedlings per square foot since a higher level would tend to produce spindly stock and a lower level may not be justified economically (Stoeckler and Jones, 1957). Dry weight production varied from a low of 22 grams per square foot for white spruce to 255 grams per square foot for red pine, while the suggested level for all three 
species is approximately 100 grams per square foot (Lunt, 1938). Since a soil is capable of only a certain level of organic matter production, an inverse relationship is indicated between seedling quality and stocking density.

The results of analysis of the seedlings for their level of nutrients indicate a similar lack of correlation with quality when the nutrients in the seedlings are expressed on a per cent concentration or uptake in pounds per unit area of seedbed. This lack of correlation may be due to reasons similar to those expressed above concerning the results of soil analyses: several nutrient deficiencies in the soil plus variations in density of stocking. The concentrations of nutrients of the seedlings range as follows: 2-0 white spruce, nitrogen 0.87-1.75 per cent, phosphorus 0.09-0.13 per cent, potassium 0.14-0.42 per cent, calcium $0.42-0.66$ per cent, magnesium $0.09-0.16$ per cent; $2-0$ white pine, nitrogen 1.21-2.14 per cent, phosphorous $0.10-0.14$ per cent, potassium 0.210.51 per cent, calcium $0.17-0.61$ per cent, magnesium $0.07-0.13$ per cent; and 2-0 red pine, nitrogen 0.82-1.81 per cent, phosphorus 0.09-0.13 per cent, potassium 0.17-0.56 per cent, calcium $0.16-0.37$ per cent, magnesium 0.08 0.16 per cent.

Expression of nutrient uptake on a per seedling basis results in linear trends in the relationships between nitrogen, phosphorus, calcium and magnesium contents, and the quality indices (Table 2). Since larger seedlings, unless abnormally developed, are of higher quality, the seedling quality index reflects dry matter production. The nutrient uptake on a per seedling basis is related to dry matter production. Thus, the contents of nutrients per seedling are closely, but not completely, related to the quality index. Since the index includes the modifiers of height-diameter quotient and top-root ratio, several instances occur in Table 2 where nutrient contents do not correlate with the appropriate indices.

\section{CONCLUSION}

Seedling quality is affected by the two environmental factors of nursery soil fertility level and density of stocking. It is possible to maintain high quality stock supported by soils of relatively poor fertility by maintaining low seedling density. However, sustained economic production of stock can only be maintained by controlling stocking density and soil fertility levels.

At a given stocking density, the quality index, when further refined, should provide an indication of weaknesses in the soil management program which would then need detailed investigation through soil and stock analyses.

\section{Literature Cited}

DICKSON, A., LEAF, A. L. and J. F. HOSNER. 1960. Quality appraisal of white spruce and white pine seedling stock in nurserics. For. Chron. 36:10-13.

LUNT, H. A. 1938. The use of fertilizer in the coniferens nursery with special reference to Pinus resinosa. Bull. Conn. Agric. Exp. Sta. 416: 722-766.

STOECKLER, J. H. and G. W. JONES. 1957. Forest nursery practice in the Lake States. Agric. Hdbk. 110, Govt. Print. Office, Wash. D.C.

WILDE, S. A. 1958. Forest soils. Ronald Press. New York, N.Y.

WILDE, S. A. and G. K. VOIGT. 1955. Analysis of soils and plants for foresters and horticulturists. J. W. Edwards. Ann Arbor, Mich. 
TABLE 2

Relationship of Seedling Production and Analysis to Seedling Quality Indices of 2-0 White Spruce, White Pine and Red Pine in

Four Northeastern U.S. Nurseries

\begin{tabular}{|c|c|c|c|c|c|c|c|c|}
\hline \multirow{3}{*}{$\begin{array}{l}\text { Quality } \\
\text { Seedling } \\
\text { Quality } \\
\text { Index }\end{array}$} & \multirow[b]{2}{*}{$\begin{array}{l}\text { Seedling } \\
\text { Density }\end{array}$} & \multirow{2}{*}{$\begin{array}{c}\text { Seedling } \\
\text { Dry-Wt. } \\
\text { Prrdaction }\end{array}$} & \multirow{3}{*}{$\frac{\text { Reaction }}{\mathbf{p H}}$} & \multicolumn{5}{|c|}{ Seedling Analysis } \\
\hline & & & & $\mathbf{N}$ & $\mathbf{P}$ & $\mathbf{K}$ & $\mathbf{C a}$ & $\mathbf{M g}$ \\
\hline & No./sq. ft. & g./sq. ft. & & \multirow{2}{*}{\multicolumn{5}{|c|}{ Milligrams per seedling }} \\
\hline \multicolumn{6}{|c|}{ 2-0 WHITE SPRUCE } & & & \\
\hline .46 & 12 & 32.5 & 5.4 & 47.5 & 3.5 & 6.2 & 14.1 & 2.7 \\
\hline .25 & 26 & 40.0 & 5.3 & 26.6 & 1.7 & 3.5 & 6.5 & 1.5 \\
\hline .20 & 26 & 32.0 & 5.5 & 20.8 & 1.5 & 2.7 & 5.4 & 1.1 \\
\hline .15 & 56 & 50.4 & 4.7 & 14.8 & 1.0 & 1.6 & 4.0 & 0.8 \\
\hline .14 & 62 & 58.3 & 4.8 & 14.9 & 1.0 & 2.3 & 4.7 & 1.0 \\
\hline .11 & 63 & 53.5 & 4.7 & 14.7 & 0.8 & 2.7 & 4.2 & 0.8 \\
\hline .070 & 94 & 51.7 & 4.8 & 5.7 & 0.5 & 2.2 & 3.3 & 0.7 \\
\hline .065 & 135 & 79.6 & 4.7 & 6.0 & 0.6 & 2.5 & 3.4 & 0.9 \\
\hline .061 & 105 & 38.8 & 5.1 & 5.2 & 0.3 & 0.5 & 2.0 & 0.5 \\
\hline .056 & 63 & 22.7 & 4.9 & 5.3 & 0.4 & 0.5 & 2.4 & 0.5 \\
\hline .046 & 118 & 59.0 & 4.8 & 4.3 & 0.6 & 2.4 & 2.5 & 0.7 \\
\hline .038 & 189 & 25.7 & 5.1 & 3.6 & 0.2 & 0.4 & 1.3 & 0.3 \\
\hline \multicolumn{9}{|c|}{ 2-0 WHITE PINE } \\
\hline .27 & 39 & 54.2 & 4.5 & 17.5 & 1.8 & 3.3 & 2.4 & 1.2 \\
\hline .22 & 44 & 66.9 & 4.5 & 25.8 & 1.8 & 3.5 & 2.7 & 1.1 \\
\hline .19 & 91 & 128.3 & 4.5 & 25.9 & 2.0 & 3.7 & 2.4 & 1.3 \\
\hline .15 & 95 & 64.6 & 4.3 & 9.2 & 0.7 & 3.3 & 2.2 & 0.6 \\
\hline .13 & 73 & 62.8 & 4.3 & 10.4 & 1.0 & 4.4 & 2.0 & 1.0 \\
\hline .12 & 91 & 67.3 & 4.4 & 11.0 & 0.9 & 1.8 & 2.5 & 0.5 \\
\hline .11 & 137 & 100.0 & 4.4 & 11.1 & 0.8 & 3.4 & 3.1 & 0.9 \\
\hline .11 & 59 & 29.5 & 4.4 & 7.1 & 0.5 & 2.2 & 1.6 & 0.4 \\
\hline .082 & 71 & 34.8 & 4.3 & 7.1 & 0.5 & 1.1 & 1.3 & 0.6 \\
\hline .057 & 78 & 24.2 & 4.7 & 5.7 & 0.4 & 0.6 & 1.9 & 0.4 \\
\hline .054 & 93 & 26.0 & 4.7 & 5.1 & 0.4 & 0.7 & 1.2 & 0.4 \\
\hline .042 & 120 & 30.0 & 4.6 & 5.3 & 0.3 & 0.6 & 1.2 & 0.3 \\
\hline \multicolumn{9}{|c|}{ 2-0 RED PINE } \\
\hline .31 & 37 & 119.9 & 4.2 & 40.8 & 3.6 & 10.7 & 4.9 & 2.9 \\
\hline .19 & 164 & 254.2 & 4.1 & 12.7 & 1.4 & 3.2 & 2.2 & 1.4 \\
\hline .16 & 172 & 196.1 & 4.3 & 15.0 & 1.4 & 4.3 & 1.9 & 1.0 \\
\hline .11 & 102 & 50.0 & 4.2 & 6.4 & 0.5 & 2.1 & 1.0 & 0.5 \\
\hline .083 & 75 & 30.0 & 4.2 & 5.3 & 0.4 & 2.0 & 0.7 & 0.4 \\
\hline .067 & 205 & 45.1 & 4.7 & 4.0 & 0.2 & 0.4 & 0.6 & 0.2 \\
\hline .056 & 201 & 40.2 & 4.7 & 3.4 & 0.2 & 0.3 & 0.5 & 0.2 \\
\hline .054 & 177 & 58.4 & 4.3 & 5.8 & 0.4 & 1.0 & 0.8 & 0.4 \\
\hline .049 & 97 & 22.3 & 4.2 & 3.0 & 0.3 & 1.3 & 0.4 & 0.2 \\
\hline .047 & 185 & 64.7 & 4.4 & 6.3 & 0.3 & 1.1 & 0.7 & 0.5 \\
\hline .046 & 182 & 54.6 & 4.3 & 5.3 & 0.2 & 0.6 & 0.5 & 0.2 \\
\hline .038 & 189 & 32.1 & 4.7 & 2.6 & 0.2 & 0.6 & 0.7 & 0.3 \\
\hline
\end{tabular}

